\title{
O CINEMA E O DIREITO: UMA VISÃO PRÁTICA DO USO DO RECURSO CULTURAL NOS CURSOS PREPARATÓRIOS PARAA MAGISTRATURA E NAS FORMAÇÕES DE MAGISTRADOS
}

\section{MOVIES AND THE LAW: A PRACTICAL VISION OF THE USE OF A CULTURAL RESOURCE AT THE MAGISTRACY PREPARATORY COURSES AND MAGISTRATES TRAINING}

\section{Gabriel Henrique Collaço ${ }^{1}$}

Resumo: O presente artigo apresenta a estratégia do uso do cinema em sala de aula como recurso didático. A estratégia integra o plano de técnicas criativas de cursos de preparação e formação de magistrados que envolvem a redação jurídica. O objetivo é mostrar como ocorre o trabalho com o uso do cinema para a mobilização dos mecanismos sensoriais nos participantes e mudanças na redação de textos jurídicos e, ainda, apresentar estratégias aos professores que desejam trabalhar com o recurso audiovisual, no caso, o cinema. Assim, com o uso do cinema em sala de aula, os estudantes e professores percebem a construção da narrativa cinematográfi- ca em determinado contexto, avaliam, criticam e identificam elementos que trazem reflexões sobre a vida em sociedade e sobre as possíveis produções textuais, além das noções básicas de audiovisual em suas formações para o exercício da magistratura.

Palavras-chave: Cinema e direito. Redação jurídica. Formação de magistrados.

\begin{abstract}
This article presents the strategy of the use of the movies in the class as a didactical resource. The strategy integrates the plan of creative techniques in the courses of magistrates preparation and training that involves legal writing. The objective is to
\end{abstract}

1 Jornalista Profissional, especialista em Jornalismo Cultural pela Pontifícia Universidade Católica de São Paulo (PUC/SP), especialista em Metodologia para a Educação a Distância e em Docência do Ensino Superior pela Universidade do Sul de Santa Cataria (Unisul). Professor de cursos de graduação e pós-graduação da Unisul e assistente de pós-graduação da Gerência de Ensino, Pesquisa e Extensão (GEPEx/ Unisul). Professor, assessor pedagógico e de comunicação da Escola Superior da Magistratura do Estado de Santa Catarina (Esmesc). Autor de livros e de material didático. E-mail: gabriel@esmesc.org.br 
show how is the work with the use of movies to mobilize the sensorial mechanisms in the participants and the changes in the composition of the legal texts and also to present strategies to the teachers who willing to work with audiovisual resources, in this case, the movies. Thus, with the use of movies in the class, the students and teachers realize the cinematographic narrative construction in a particular context, they evaluate, criticize and identify elements that may bring reflections about life in society and about the possible textual productions, besides the audiovisual basic notions in their training to the magistracy exercise.

Keywords: Movies and law. Didactical resource. Legal writing.

\section{INTRODUÇÃO}

O presente artigo tem por objetivo apresentar resultados de pesquisa realizada, desde 2012, com turmas do curso de Preparação para a Magistratura, da Escola Superior da Magistratura do Estado de Santa Catarina e, também, de cursos de Formação de Formadores, como por exemplo o ocorrido na Academia Judicial do Tribunal de Justiça de Santa Catarina, em 2016, que tiveram o cinema como estratégia de mobilização do grupo para a escrita de textos narrativos. $\mathrm{O}$ objetivo do estudo foi o de verificar como a narrativa do cinema mobiliza os participantes na construção de textos.

Para isso, criaram-se metas para alcance de um resultado pertinente para a pesquisa: a) identificar as características da redação técnica e dos níveis de linguagem utilizados pelos estudantes em fase inicial de preparação para o concurso da magistratura e em formação de magistrados; b) desenvolver a produção de textos narrativos a partir de temática de cenas do filme; c) identificar os sete elementos de uma narrativa nos textos escritos a partir da assistência de filmes propostos; e) verificar se houve ampliação nos níveis de linguagem dos acadêmicos em relação ao que aparecia nos textos iniciais.

Nesse sentido, com o uso do cinema em sala de aula, os acadêmicos, magistrados e professores percebem a construção da narrativa cinematográfica em determinado contexto, avaliam, 
criticam e identificam elementos que trazem reflexões sobre a vida em sociedade e sobre as possíveis produções textuais, além das noções básicas de audiovisual em suas formações.

A ideia de levar o cinema para as aulas, nos cursos que envolvem produção de textos, surgiram pela necessidade de efetuar um trabalho efetivo em relação à construção textual, de forma que possibilitasse ao participante diferentes visões de estrutura e linguagens e também não só a partir da leitura de obras impressas.

Sendo assim, partiu-se da seguinte problemática para a viabilização da pesquisa: como usar o cinema em sala de aula para o aprimoramento dos mecanismos sensoriais nos estudantes participantes? Como estes admitem as tarefas em um ambiente de trabalho a partir das ações, e como realizam as atividades para a concretização de resultados e mudanças na redação de textos?

Ressalta-se que o cinema é um recurso educativo, pois tem características de um discurso com utilização de estratégias de comunicação para expor conteúdos. Os estudantes, em cursos preparatórios ou de formação, necessitam de apoio para debates de vivências contemporâneas, para o conhecimento de procedimentos do texto jurídico e de textos de legislação e jurisprudencial. Para isso, o cinema corrobora com a formação dos participantes-estudantes-magistrados que sejam capazes de ler, interpretar, analisar, escrever e falar de forma crítica, além de estabelecer relações e integra-se aos assuntos propostos nas películas.

Enfim, o que se pretende é colaborar com o processo educativo nas escolas e nas formações de magistrados, sendo esta uma proposta criativa. $\mathrm{O}$ uso do cinema vem sendo discutido há muito tempo por teóricos. No Direito, a discussão está agregada ao gênero das películas direcionadas ao assunto jurídico. Como ferramenta de técnica no ensino jurídico para a construção e produção textual, o uso do cinema ainda pode ser considerado 
novo, pois é uma estratégia de ensino adequada às novas características dos estudantes no exercício na academia e atividades profissionais e pessoais. A diversidade de modalidades, gêneros e regiões acabam trazendo para o ambiente das escolas e formações as discussões visuais e as narrativas para a construção também de novas realidades na magistratura, com linguagens mais humanas e éticas.

Para este trabalho foram utilizadas cenas dos primeiros 9 (nove) minutos do filme "O fabuloso destino de Amélie Poulain", película francesa em que é narrada a história da jovem Amélie. A sinopse do filme aponta que, após deixar a vida de subúrbio, a inocente Amélie (Audrey Tautou) muda-se para o bairro parisiense de Montmartre, onde começa a trabalhar como garçonete. Certo dia encontra uma caixa escondida no banheiro de sua casa e, pensando que pertencesse ao antigo morador, decide procurá-lo e é assim que encontra Dominique (Maurice Bénichou). Ao ver que ele chora de alegria ao reaver o seu objeto, a moça fica impressionada e adquire uma nova visão do mundo. Então, a partir de pequenos gestos, ela passa a ajudar as pessoas que a rodeiam, vendo nisso um novo sentido para sua existência.

Para a realização da pesquisa, no tocante à metodologia, entendeu-se necessário o uso da pesquisa-ação, pois ela não serve apenas para resolver problemas, mas também para compreender e melhorar a prática educativa. Assim sendo, a pesquisa-ação não consiste em simples levantamento de dados e relatórios como muitos pensam. Ao ser adotado o tipo de ação, o pesquisador desempenha um papel ativo na própria realidade dos fatos observados. O uso dos conceitos da ergonomia, como elemento do processo para análise de uma situação de trabalho, mostra neste caso que não há um modelo predeterminado da ação. $\mathrm{O}$ que se pretende futuramente é usar o método de análise ergonômica do trabalho para fornecer melhoria do 
conteúdo das tarefas e da própria organização do trabalho a partir das ações.

Importante conceituar tarefa e atividade para que os conceitos ergonômicos fiquem visíveis desde a introdução deste artigo. Segundo Abrahão e outros (2009, p. 49-52) tarefa é aquilo que estabelece a organização do trabalho ou a prescrição para o trabalho a ser realizado. A atividade é aquilo que o sujeito realmente realiza para atingir os objetivos prescritos.

Sendo assim, o artigo resume-se na demonstração de uma realidade documentalmente comprovada e problematizada. Estudo do conjunto de fatores presentes, refletidos ou projetados no produto observado, no caso a sala de aula em cursos preparatórios e de formação de magistrados.

\section{A MOBILIZAÇÃO DA ESCRITA A PARTIR DE RECURSO CULTURAL}

Percebe-se, assim que iniciados os processos da situação de trabalho com o uso do cinema em sala de aula, que quando bem utilizados, os recursos audiovisuais são enriquecedores e atraem a atenção dos estudantes. Isso porque se tem a oportunidade de diversificar os estímulos sensoriais. Conforme Mirzoeff (1999, p. 1, apud SEVCENKO, 2001, p. 123):

A experiência humana está mais submetida hoje aos estímulos visuais e aos processos de visualização do que jamais esteve, das imagens transmitidas via satélite ao escaneamento das minúcias interiores do corpo humano. [...]. Em meio a esse turbilhão de imagens, ver significa muito mais que acreditar. As imagens não são mais uma parte da vida cotidiana, elas são a vida cotidiana.

Os recursos culturais, como o cinema e as artes em geral, constituem algumas técnicas que podem ser utilizadas em sala de aula. Pensando nisso, foi criada uma estratégia para viabi- 
lizar a construção textual em cursos preparatórios e de formação de magistrados. Com o auxílio da tecnologia e com o uso do cinema como recurso mobilizador, os estudantes se tornam participantes ativos, falando mais, ouvindo mais, vendo mais e, consequentemente, refletindo mais sobre os diversos caminhos para a elaboração de textos com qualidade técnica.

[...] as situações de trabalho são compreendidas como sendo constituídas pelas instalações físicas e materiais disponíveis no ambiente que compõe o cenário de trabalho, tais como equipamentos, instrumentos, mobiliário, iluminação, exposição a ruídos e gases, entre outros. Esses fatores estão constantemente em interação, podendo facilitar ou dificultar a realização do trabalho. Eles constituem uma unidade de análise do contexto de produção e também um determinante do trabalho. (ABRAHÃO et al., 2009, p. 47).

Como temática da prática docente, optou-se pelo uso do cinema como elemento mobilizador na construção de textos. Utilizou-se o verbo mobilizar por entender a mobilização como fenômeno que envolve o todo do sujeito. No entendimento de Vasconcellos (2005, p. 59, grifo do autor), "a mobilização corresponde a sensibilização para o conhecimento, a criar uma atitude favorável à aprendizagem".

Um exemplo é a matéria de ensino Redação Jurídica que na matriz curricular da Escola Superior da Magistratura do Estado de Santa Catarina (ESMESC) está posta no Módulo II, conforme a grade constante do Projeto Político-Pedagógico. A matéria de ensino faz parte da formação fundamental para o ingresso na carreira da magistratura. Em sua ementa, possui a parte de compreensão e análise crítica de texto, além da produção de texto em diferentes gêneros e modalidades, incluindo a redação de sentença. A justificativa da disciplina expõe que os estudantes necessitam compreender, interpretar e interagir de forma que haja um entendimento mútuo. Para isso, criou-se também a estratégia do uso do cinema no ensino. No entendi- 
mento de Vasconcellos (2005, p. 62),

[...] a primeira grande preocupação que o educador deve ter na construção do conhecimento: a proposta de trabalho deverá ser significativa para o educando, sendo esta uma condição para a mobilização para o conhecimento. Se a mobilização é meta, a significação é o caminho.

O Projeto Pedagógico da ESMESC (2016) traz o entendimento de formação do estudante não apenas técnico, mas, também, nos aspectos ético, político e estético e em todos os outros capazes de fazê-lo situar-se consigo mesmo e com o mundo cada vez mais complexo e célere nas transformações.

Conforme Teixeira e Lopes (2003, p. 10) "o cinema participa da história não só como técnica, mas também como arte e ideologia. Ele cria ficções e realidades históricas e produz memória". Os autores ainda completam afirmando que o cinema deve ser usado como meio para exploração de problemas complexos dos nossos tempos, uma forma de expor e interrogar a realidade (TEIXEIRA; LOPES, 2003).

Sempre importante pensar o papel pedagógico com potencialidades didáticas, ao utilizar as novas tecnologias, as quais não substituem a interação pessoal, porém a complementam ou então constituem seu instrumento. Além disso, a vinculação da teoria e da prática nas atividades pedagógicas. Nesse sentido, o cinema corrobora com a ideia de que os cursos de preparação e de formação também são ambientes de promoção de ações diferenciadas e propícios aos diversos tipos de desenvolvimentos, sejam físicos ou mentais, para o crescimento afetivo, estético, emocional e intelectual.

Nos estudos de Álvaro Vieira Pinto (2005, p. 213) estão expostos dois momentos que corroboram com o objetivo das estratégias de docência nesta pesquisa:

[...] com poesia e a narrativa fictícia, que constituem extensões com caráter imaginativo do uso produtivo da palavra 
na transmissão de comunicações entre membros do grupo em estágio primitivo de hominização, para efeito do trabalho com finalidade de subsistência. [...] a finalidade, pertencente em princípio a um ato vital coletivo imprescindíveis, com o tempo torna-se interesse da atuação de alguns indivíduos, especializados por suas tendências, e termina, por força do uso cultural, por adquirir valor estético positivo, definitivamente fixado enquanto atividade criadora distinta.

E o cinema, expõe Aumont (2008, p. 08), "é mais que uma máquina, mas traz na sua natureza um maquinismo intrínseco que a maior parte das artes ignora. [...] o cinema é estilo que varia em máquinas de tecnologias diversas".

\section{O CINEMA, O DIREITO E AS AÇÕES DIDÁTICAS}

O cinema pode ser utilizado como recurso cultural, pois assistir a película é uma oportunidade para conhecer novas culturas, ter visões diferenciadas e aprimorar o conhecimento. O principal tópico a definir na docência foi o objetivo que se pretendeu atingir com a reprodução do material cinematográfico. Em nenhuma hipótese foi pensado o uso do cinema para preencher o espaço de tempo de aula.

Corroborando com o pensamento, ditam Teixeira e Lopes (2003, p. 10): 'também não se trata de 'escolarizar' o cinema ou de 'didatizá-lo'. Não queremos concebê-lo e restringi-lo a um instrumento ou recurso didático-escolar, tornando-o como uma estratégia de inovação tecnológica na educação e no ensino". Conforme os autores, isso é uma redução extrema. "O cinema por si só permite a experiência estética porque fecunda e expressa dimensões da sensibilidade, das múltiplas linguagens e inventividade humana". (TEIXEIRA; LOPES, 2003, p. 11).

Segundo Deisy Ventura (2004, p. 92) “o cinema permite o professor atravessar épocas e fronteiras, além de oferecer subsídios a valiosas análises comportamentais. A organização de um cineclube ou de ciclos temáticos de cinema, com 
posterior discussão da película exibida, produz efeitos certeiros e duradouros".

No entendimento de Almeida (2001, p. 49-50, apud CARVALHO), o cinema faz parte da cultura e assim

obedece a condições de produção e de mercado e não a objetivos pedagógicos. E, nesse sentido, seria interessante incluir o estudo e a análise do cinema na educação quando esta é percebida em um contexto mais amplo do que o do interior de um campus universitário [uma escola de magistratura]. Levar o cinema para dentro da sala de aula significa retirar alguns 'muros' que separam as instituições de ensino superior do mundo que as cerca. A projeção de filmes pode estimular debates e reflexões críticas dos estudantes acerca de fatos e problemas históricos, culturais, sociais, econômicos e políticos da sociedade.

$\mathrm{O}$ ato comunicativo é um ato de aprendizagem. Para isso, foi necessário criar uma série de tópicos, chamados aqui de "Ações", para explicar e nomear cada um dos passos da atividade de produção textual.

A inserção do cinema pode trazer vários benefícios para o processo de ensino-aprendizagem e envolve os estudantes e, ao mesmo tempo, tornando o trabalho mais agradável, pois estes já possuem contato com o cinema no cotidiano fora da sala de aula.

[...] o cinema é uma forma de criação artística, de circulação de afetos e de fruição estética. É também uma certa maneira de olhar. É uma expressão do olhar que organiza o mundo a partir de uma idéia sobre esse mundo. Uma idéia histórico-social, filosófica, estética, ética, poética, existencial, enfim. Olhares e ideias postas em imagens em movimento, por meio dos quais compreendemos e damos sentido às coisas, assim como as ressignificamos e expressamos". (TEIXEIRA; LOPES, 2003, p. 10).

Sendo assim, para a estratégia de ensino foi criada a série de "Ações" que se integram durante os cursos preparatórios ou 
formações. As funções de informação, de mobilização e de expressão são propostas de diversas ações. Ver, ouvir, sentir. Trabalhar com os órgãos sensoriais. Uma reeducação do "olhar" do estudante, acionando e estimulando o processo de criação. Enfim, a proposta é interrogar os sentidos. Uma nova leitura para as imagens, os sons, os movimentos. Para Falzon (2007, p. 213), “[...] o sujeito, em sua atividade, está igualmente em relação consigo mesmo: se ele conhece, se gere e ele mesmo se transforma. [...] as mediações reflexivas que dizem respeito à relação do sujeito consigo mesmo, mediada por instrumento".

Mudanças no plano de aula e das ações do projeto de docência foram necessárias no desenvolver das aulas e da pesquisa. Lembra-se aqui dos ensinamentos de Falzon (2007, p. 213):

O conjunto das mediações intervém tanto na atividade produtiva quanto na atividade construtiva, cujas orientações e horizontes temporais são muito diferentes:-a temporalidade da atividade produtiva é a da realização das tarefas. Seu horizonte é aquele de tal ou qual ação ou cadeia de ações, correspondendo a uma missão (dada, prescrita ou esperada do trabalhador) ou a um projeto do sujeito. - a temporalidade da atividade construtiva é a do desenvolvimento, da gênese. $\mathrm{O}$ horizonte das atividades construtivas é aquele do desenvolvimento do sujeito, da personalidade, do profissionalismo.

Em se tratar de trabalho com uso da "Sétima Arte", foram pensados em planos de aula em cursos de preparação e de formação, conforme a peculiaridade de cada turma, 7 (sete) "Ações", as quais podem ser utilizadas aleatoriamente, dependendo de cada tipo de curso. Passa-se a apresentação das "Ações" nas subseções.

\subsection{Ação um}

No primeiro encontro, após a apresentação do conteúdo programático e do docente, é início de construir um pensamen- 
to de mobilização nos estudantes. Nesse sentido, é apresentado o programa do conteúdo da aula e exposto o primeiro filme, em formato de animação. É o momento de percepção do uso do cinema em sala de aula. A animação "The art of survival" traz um camaleão-aluno que em sala de aula-na floresta-está desatento e não presta atenção aos ensinamentos do camaleão-professor. Depois de não conseguir a mutação de cor, ensinada pelo professor na lousa, o camaleão tem o pensamento de buscar alternativas no momento em que uma águia está pronta para o ataque. Amarelo-deveria estar verde igual às plantas -, o camaleão-aluno encontra a alternativa de jogar-se em cima de um ônibus escolar da mesma cor. Assim, segue para o meio urbano e é descoberto por um artista plástico, que ao final, com as percepções das peculiaridades de mutação diferenciada do camaleão [que até listrado e xadrez fica], faz obras de arte com as imagens que vê e torna este uma celebridade. Nesta Ação UM é feito debate em aula, expositivo-dialogada, da importância da busca do novo e das peculiaridades de cada acadêmico. Assim como o camaleão, eles terão de se deparar com diferente habitat e situações na magistratura.

\subsection{Ação dois}

A mudança de habitat começa a acontecer. Os estudantes percebem que ao chegar nas escolas ou nas formações mudam as formas de leituras e também as percepções iniciais sobre a produção textual. Nesse rumo, surgem os diversos tipos de leitores e é solicitada (para o próximo Procedimento) a leitura do texto de Lucia Santaella, "A Leitura fora do livro", que está disponível na Internet, para que estes tenham diferentes convivências com as tecnologias e percebam as características dos tipos de leitores. Para o despertar da curiosidade, é exibida mais uma animação "Média", a qual trata da velocidade da informação nos tempos tecnológicos. 


\subsection{Ação três}

Com indagações sobre os tipos de leitores, passa-se para a construção do texto narrativo. Depois de trabalhar com os sete elementos da narração, surge a tarefa com base na assistência de cenas do filme francês "O fabuloso destino de Amélie Poulain”. São passadas algumas cenas iniciais do filme e os estudantes têm de contar, de forma escrita, com suas próprias palavras, as trajetórias da personagem. É criado o primeiro texto individual e feita a primeira análise da produção textual pelos próprios acadêmicos. Eles relatam os pontos positivos e negativos da produção textual em folha de avaliação.

\subsection{Ação quatro}

A Ação QUATRO tem por base trabalhar com questões de percepção, de estabelecimento de relações e de intuição. Os alunos assistem ao depoimento da artista plástica Fayga Ostrower sobre questões de criação e intuição no filme documentário "Janela da Alma", o qual retrata questões da visão. Nesta ação são trabalhadas as visões diferentes sobre a película da ação anterior ["O fabuloso destino de Amélie Poulain”]. Os estudantes leem os textos e percebem o quanto cada um teve percepções diferentes sobre a película. Logo após alguns exporem o material confeccionado, foram novamente apresentadas as cenas do filme para o aperfeiçoamento do texto a partir de novas percepções e para que os alunos pudessem inserir descrições de ambientes e personagens. O texto, preponderantemente narrativo, é guardado para que seja aperfeiçoado em outro momento de tarefas.

\subsection{Ação cinco}

$\mathrm{Na}$ ação CINCO é momento de trabalhar os níveis de linguagem expostos nos textos. Depois das leituras, assiste-se novamente ao filme "O fabuloso destino de Amélie Poulain". 
Volta-se então para a verificação dos pontos negativos de auto avaliação da ação TRÊS e para também saber se estes foram superados. Nesse momento os estudantes preenchem outra parte da avaliação. Mostram os pontos do texto inicial, do texto atual e o que pretendem como texto ideal.

\subsection{Ação seis}

Surge a ação SEIS. Até esta aula, os estudantes tiveram de fazer a leitura obrigatória do livro "O judiciário ao alcance de todos: noções básicas de juridiquês". O texto está disponível também no site da Associação dos Magistrados do Brasil (AMB). Na aula, com o apoio do audiovisual, são assistidas cenas do documentário "Justiça", de Maria Augusta Ramos, em que a desembargadora Fátima Clemente e a defensora pública Maria Ignez Kato falam da linguagem no Direito. É momento de trabalhar a linguagem grupal técnica, própria das ciências e profissões. O debate encaminha para a análise dos termos utilizados nos textos preponderantemente narrativos confeccionados a partir do filme "O fabuloso destino de Amelie Poulain". Os estudantes iniciam o processo de preparação para a confecção da parte "dos fatos" de uma petição inicial. Nessa tarefa, eles relacionam leitura do texto do "Juridiquês" com as falas das operadoras do Direito e ainda verificam uma cena completa do filme documental que se passa no Tribunal de Justiça do Rio de Janeiro. Assim, percebem as diferenças e semelhanças da construção de produção textual em diferentes níveis de linguagem. Isso colabora, e muito, para o aperfeiçoamento e simplificação da linguagem na atividade judicante.

\subsection{Ação sete}

A Ação SETE ainda é inédita, pois não foi aplicada em aula, mas é programada para o projeto de docência envolvendo o cinema. Ela é pensada para a apresentação final das 
narrativas. $\mathrm{O}$ trabalho deve ser aplicado oralmente em sala de aula e ser feita a avaliação final do processo de criação. Importante salientar que muitas oportunidades de avaliação do processo ocorreram, colaborando para o andamento da aplicação dos resultados da pesquisa. Outras oportunidades de discussões sobre a docência com o uso do cinema foram possibilitadas no decorrer da pesquisa, como por exemplo a Formação de Formadores sobre "Plano de Ensino, Linguagem e Comunicação", na Academia Judicial do Tribunal de Justiça do Estado de Santa Catarina, em 2016. Nesses importantes momentos educacionais, podem-se avaliar os processos das tarefas e atividades e transformar a própria docência. Sendo assim, a ação SETE permanece inédita sem as conclusões serem prejudicadas. Enfim, este é o caminhar de uma pesquisa-ação.

\section{A DOCÊNCIA E O CONSTANTE REPLANEJAMENTO}

No tocante à problematização, o ensino da produção textual, com diferentes leituras e interpretações, impõe desafios ao professor e aos estudantes, exigindo a necessidade de trazer para o ambiente de sala de aula meios que facilitem a produção textual dos participantes do processo de aprendizagem por meio de tarefas.

A problematização foi adequada no momento de aplicação da docência, havendo, claro, a necessidade de (re)planejar apenas o tempo de aplicação, pois os cursos possuem cargas-horárias diferentes, o que altera cada cronograma e aproveitamento de ações.

Outro problema bastante desgastante para o docente está relacionado aos equipamentos tecnológicos necessários para a aplicação do cinema em sala de aula. Tem que ser ter o domí- 
nio deles para salvar arquivos, reservar equipamentos audiovisuais. Sempre aparece um problema com áudio ou softwares. Momentos de falta de equipamentos, como o controle de ligar o datashow, problemas no sistema de reserva e também de logística pelos próprios responsáveis. É necessário sempre estar atento. Claro que, em todo momento, se buscou (re)planejamento da docência quando da falta de tecnologias ou até a sua instalação correta.

Para não parecer apenas uma reclamação de pesquisador, fundamenta-se: "Seria bom que todas as instituições de ensino [...] tivessem espaço e equipamentos adequados para a exibição regular de filmes, com uma programação orientada tanto para o entretenimento [...] quanto para o ensino." (DUARTE, 2002, p. 95).

Salienta-se que o pesquisador, antes da aplicação das ações, tomou o cuidado de efetuar as reservas e ver as possibilidades de uso dos locais adequados da instituição. Aliás, isso é um ponto importante para o uso do cinema em sala de aula. "Deve-se verificar a estrutura dos equipamentos para uso de audiovisual nas instituições de ensino. Os locais em que podem ser projetados os filmes [...] podem modificar substancialmente o trabalho pedagógico", ensina Carvalho (2007, p. 72).

\section{CONCLUSÃO}

Os estudantes, magistrados e professores mostraram-se bastante receptivos ao uso da tecnologia em sala de aula. Em um mundo em que as imagens modificam os tipos de leitores e, consequentemente, a escrita, o uso de cinema colabora para que novas visões e culturas sejam mostradas na tela, para interpretação textual e para o aguçar do pensamento de quem assiste sobre determinado tema, em um lugar, em algum tempo e com características culturais diversas. 
A construção textual torna-se mais prazerosa. As mudanças de atitudes de procedimentos éticos e cuidados com a redação técnica são perceptíveis após o uso do cinema como mobilizador para construção de textos narrativos. Com cada ação instituída e pensada, torna-se importante incentivar a participação dos estudantes, magistrados e professores, fazendo-os expor suas ideias, complementar informações, responder e questionar sobre o que está sendo lecionado. Isto é, verificar as atividades realizadas.

Atualmente, é interessante o trabalho como professor formador "problematizador". As estratégias despertam o senso crítico e fazem com que os estudantes percebam a criação e a concretização de algo que eles próprios realizaram. Eles saem da passividade de uma aula expositiva, ainda muito utilizada em cursos preparatórios ou de formação, e buscam um ambiente de pesquisa, de debates, de aprofundamento de revisão de temas que nem sempre são assimilados em primeiro contato com a matéria. Abrem-se assim novos canais de comunicação, seja verbal ou não verbal. Fica a certeza de que no ambiente da sala de aula a cada dia haverá a ampliação do uso do cinema, não necessariamente com temática jurídica, mas como estratégia didática diferenciada.

A experiência propicia não só reduzir o uso do cinema como ferramenta para despertar o prazer nos acadêmicos e profissionais, entretanto para mobilizá-los a verificar as diferentes formas de comunicação e de narrativas. Em seus relatos de experiências, ainda verbais nos momentos dos debates, mostram que o caráter de utilizar o cinema em sala de aula tornou-os mais ativos às vivências estéticas e colaborou para novos estímulos sensoriais. Os filmes não foram simplesmente assistidos para mudanças morais nos cidadãos, mas para a percepção de que a profissão e o texto no Direito podem sofrer mudanças para o alcance de uma sociedade mais justa. Quem sabe, no 
século XXI, teremos cada vez mais os estudos humanísticos para o importante preparo do profissional da área jurídica.

Houve sim a possibilidade de proporcionar a facilitação de procedimentos para a construção textual, seja escrita, oral ou visual. Fica a esperança de que novas estratégias surjam nas diversas salas de aula, pois a pretensão deste artigo não foi apenas de registrar momentos de pesquisa, mas de estímulo à experimentação com os aprendizados iniciais de conceitos ergonômicos na educação.

\section{REFERÊNCIAS}

ABRAHÃO, Júlia et al. Introdução à ergonomia: da prática à teoria. São Paulo: Blucher, 2009.

AUMONT, Jacques. Moderno? Por que o cinema se tornou a mais singular das artes. São Paulo: Papirus, 2008.

ASSOCIAÇÃO DOS MAGISTRADOS DO BRASIL. O judiciário ao alcance de todos: noções básicas de juridiquês. 2. ed. Brasília: AMB, 2007.

CARVALHO, Renata Innecco Bittencourt de. Universidade midiatizada: o uso da televisão e do cinema na educação superior. Brasília: Senac DF, 2007.

DUARTE, Rosália. Cinema e educação. 2. ed. Belo Horizonte: Autêntica, 2002.

FALZON, Pierre. Ergonomia. São Paulo: Blucher, 2007.

JEUNET, Jean-Pierre. O fabuloso destino de Amélie Poulain. Longa-metragem. França, 2001.

PINTO, Álvaro Vieira. O conceito de tecnologia. Rio de Janeiro: Contraponto, 2005. V. 1 .

PROJETO POLÍTICO-PEDAGÓGICO DA ESCOLA SUPERIOR DA MAGISTRATURA DO ESTADO DE SANTA CATARINA. Florianópolis: Esmesc, 2016.

PERRENOUD, Philippe. Os ciclos de aprendizagem: um caminho para combater o fracasso escolar. Porto Alegre: Artmed, 2004.

. Dez novas competências para ensinar. Porto Alegre: Artmed, 2000.

SANTAELLA, Lúcia. A leitura fora do livro. Disponível em: <http://www.pucsp.br/ pos/cos/epe/mostra/santaell.htm>. Acesso em: 29 maio 2016.

SEVCENKO, Nicolau. A corrida para o século XXI: no loop da montanha-russa. São Paulo: Companhia das Letras, 2001.

TEIXEIRA, Inês Assunção de Castro; LOPES, José de Sousa Miguel (Orgs.). A escola 
vai ao cinema. 2. ed. Belo Horizonte: Autêntica, 2003.

VASCONCELLOS, Celso dos Santos. Construção do conhecimento em sala de aula. 10. ed. São Paulo: Libertad, 2000.

VENTURA, Deisy. Ensinar direito. Barueri, SP: Manole, 2004.

ZABALA, Antoni. A prática educativa: como ensinar. Porto Alegre: Artmed, 1998.

Artigo recebido em 16/06/2016

Artigo aprovado em 12/07/2016 